\title{
Author's Note
}

he city of Volodymyr-Volynsky has a centuries-old history, which

1 was written not only by the representatives of the predominant peoples who lived in this land since time immemorial, but also by the representatives of the national minorities that settled there. Researchers have devoted little attention, if any, to the latter groups. Thus, my modest work is aimed at filling the gaps of historical memory.

Jews paid a terrible price for the experience gained by mankind during the Second World War so that various nations could coexist on Earth. Today, after the many episodes of bloodshed caused by national intolerance, we are simply obliged to safeguard the historical memory of the Jews of Volodymyr-Volynsky, their culture, traditions, daily life, religion, distinguished individuals, and the lives and tragic fate of these people and their contributions to the city's economic and social development. They left their traces, regardless of all attempts to eradicate them. That is why I would like to help recall the history of the Jewish community of the city of Volodymyr-Volynsky and not allow it to be forgotten. May this book be a kind of monument to these people.

I cherish the hope that this book will help us build a democratic society and strengthen understanding of one another. After all, we share one and the same fate and the same Fatherland.

I am certain that this book will be a useful tool for familiarizing readers who have an interest in both the rich history of this thousandyear-old city and Jewish culture in general. 
The book is based on a large variety of available materials that I collected over several years in order to preserve the memory of one of the oldest Jewish communities in Europe. However, these materials are merely the tip of the iceberg, and there is still much work to be done. The study of this topic will help scholars rethink several events of our shared history for the sake of the future.

I realize how shocking some of the materials published here will be to many, but I am deeply convinced that this tragic history must be brought to people's attention, that their minds should not slumber and their souls should not become shallow. People should know the truth about the past. Only then will they be capable of correctly evaluating the phenomena that are taking place today.

During my conversations with residents of the city, I was often the recipient of "secret" revelations from individuals who revealed their Jewish background with some trepidation. Perhaps this book will instill in some of these people a sense of pride for their parents, grandparents, and other individuals-and the courage to stop concealing their origins, not to be ashamed of their parents, who deserve their admiration and respect, and to return to their roots.

Perhaps this book will serve as both a model for regional historians in other cities that had Jewish communities and a spur to the study of their history, since Jewish history and culture are inextricable parts of the history and culture of Ukraine.

I am profoundly grateful to everyone who assisted me in my work, all the more so because, when I first began researching this topic, precious little could be gleaned from the local regional history museum. Above all, I would like to thank those few Jewish natives of VolodymyrVolynsky who managed to survive the horrors of the Holocaust and convey the truth of what they had witnessed: Moshe Margalit; Mykhail Bass, honorary resident of Volodymyr-Volynsky; Moshe Krigser; Zippora Weinstock, Eliezer Reisfeld (Israel); and the Righteous among the Nations Mykola Mykolaiovych Vavrysevych and Maria Oleksandrivna Otsaliuk. Unfortunately, Mr. Vavrysevych did not live long enough to see my book published, nor did Halyna Serhiivna Filatova, whose reminiscences are featured in the book. 
I owe a debt of gratitude to Oleksandr Kovalchuk, with whose moral support I began working on this book; David Shkolnik (Rehovot, Israel), who translated the Hebrew-language materials for the Ukrainian edition; and Harry Feldman (Petah Tikva, Israel).

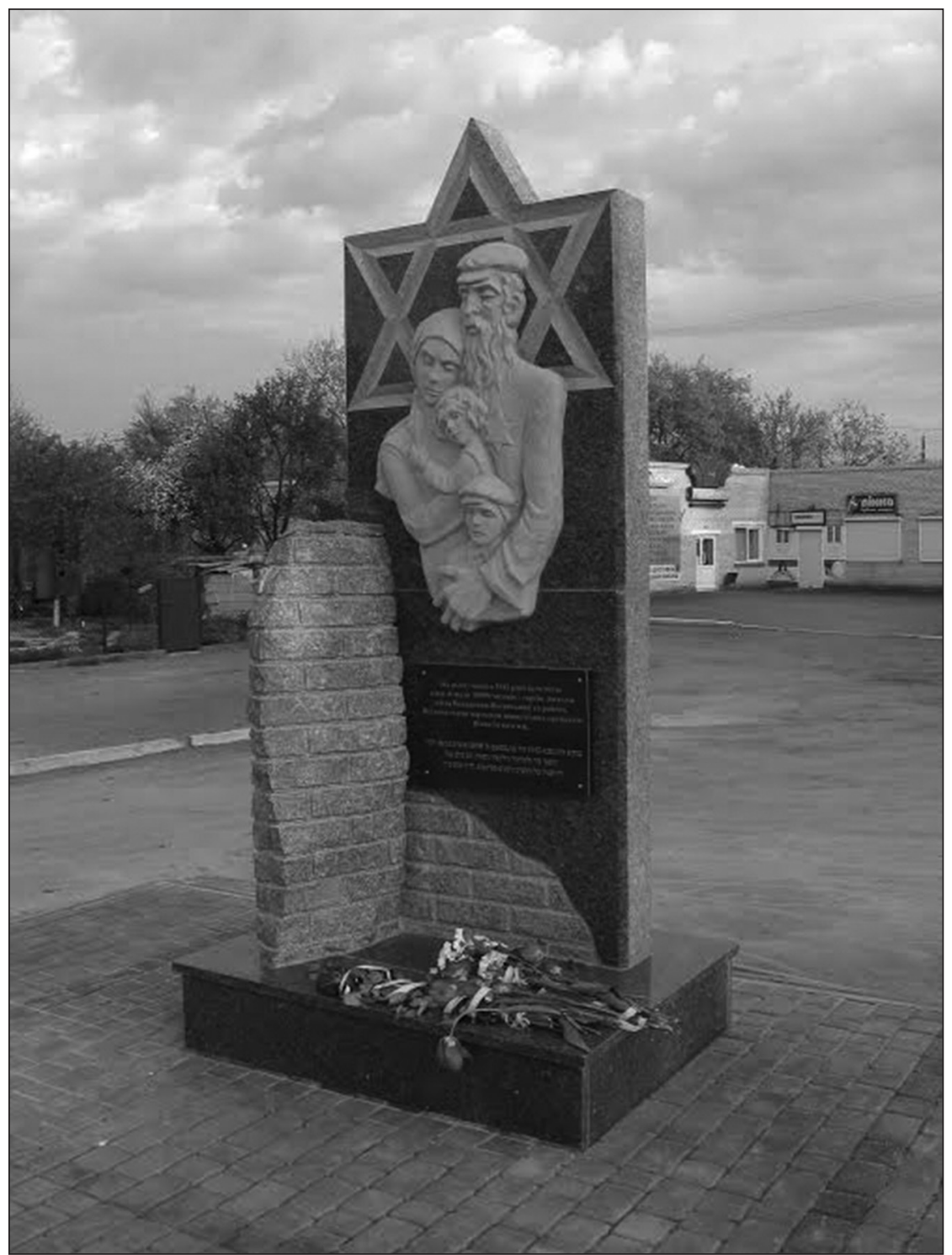

